\title{
Derivation the Schemes of Lateral and Vertical Dispersion Parameters: Application in Gaussian Plume Model
}

\author{
Mohamed M. Abdel-Wahab ${ }^{1}$, Khaled S. M. Essa ${ }^{2 *}$, Mokhtar Embaby², Sawsan E. M. Elsaid ${ }^{2}$ \\ ${ }^{1}$ Meteorology and Astronomy Department, Faculty of Science, Cairo, Egypt \\ ${ }^{2}$ Mathematics and Theoretical Physics Department, National Research Council, Atomic Energy Authority, Cairo, Egypt \\ Email: *mohamedksm56@yahoo.com
}

Received December 18, 2012; revised January 22, 2013; accepted February 3, 2013

\begin{abstract}
The main objective of this paper is to estimate the plume dispersion parameters in lateral direction $\left(\sigma_{\mathrm{y}}\right)$ and vertical direction $\left(\sigma_{\mathrm{z}}\right)$ by using power law wind speed and the scheme of eddy diffusivity in unstable condition. Comparison among our model and algebraic [1] and integral [2] formulations were held. We find that our model and two other models are in agreement with observed data.
\end{abstract}

Keywords: Dispersion Parameters; Gaussian Plume Model; Eddy Diffusivity

\section{Introduction}

The study and employment of operational short-range atmospheric dispersion models for environmental impact assessment have demonstrated to be of large use in the evaluation of ecosystems perturbation in many distinct scales [3].

In operational applications, the classical Gaussian diffusion models are largely employed in assessing the impacts of existing and proposed sources of air contaminants on local and urban air quality [4]. Simplicity, associated with the Gaussian analytical model, makes this approach particularly suitable for regulatory usage in mathematical modeling of the air pollution, such models are quite useful in short forecasting. The lateral and vertical dispersion parameters, respectively $\sigma_{y}$ and $\sigma_{z}$ represent the key turbulent parameterization in this approach. They contain the physical ingredients that describe the dispersion process and, consequently, express the spatial extent of the contaminant plume under the effect of the turbulent motion in the planetary boundary layer (PBL) [5].

In this work, we estimated the schemes of dispersion parameters in the lateral direction $\left(\sigma_{y}\right)$ and the vertical direction $\left(\sigma_{z}\right)$ in unstable stability by using wind speed in power law and comparing between our work and da (algebraic and integral formulations) with observed ta of sulfur hexafluoride (SF6) are taken from Copenhagen in Denmark.

\section{Model Formulation}

The concentration associated from point source of

*Corresponding author. strength $Q$, is expressed as [6]:

$$
\frac{C(x, y, z)}{Q}=\frac{A}{\sqrt{2 \pi} \sigma_{y} \bar{U} \bar{Z}} \exp \left(-\left(\frac{B z}{\bar{Z}}\right)^{s}\right) \exp \left(-\frac{y^{2}}{2 \sigma_{y}^{2}}\right)
$$

$C$ is the average concentration of diffusing point (x, y, z) $\left(\mathrm{kg} / \mathrm{m}^{3}\right)$.

$U$ is mean wind velocity along the $\mathrm{x}$-axis $(\mathrm{m} / \mathrm{s})$.

$x$ is along-winds coordinate measured in wind direction from the source $(\mathrm{m})$.

$y$ is cross-wind coordinate direction (m).

$z$ is vertical coordinate measured from the ground $(\mathrm{m})$.

$\sigma_{y}$ is the plume dispersion parameter in the lateral directions.

Where the value of the parameter, $\mathrm{s}$, depends on the stability ( $\mathrm{s}=0.75$ and $\mathrm{A}=1.42)$ in unstable case [7].

The mean plume height, $\bar{Z}$, is defined by

$$
\bar{Z}(x)=\frac{\int_{0}^{\infty} z C(x, y, z) \mathrm{d} z}{\int_{0}^{\infty} C(x, y, z) \mathrm{d} z}
$$

And the mean plume velocity, $U$, is defined by

$$
\bar{U}=\frac{\int_{0}^{\infty} U(z) C(x, y, z) \mathrm{d} z}{\int_{0}^{\infty} C(x, y, z) \mathrm{d} z}
$$

We assume that the mean wind speed, $U(z)$, can be described by a power law so that:

$$
U(z)=U_{r}\left(\frac{z}{Z_{r}}\right)^{p}
$$

$U r$ is a reference velocity at height $Z r$, the value of the 
power, $p$, lies between 0.15 and 0.20 in unstable case [8].

Let, $B$, be a non-zero constant, then taking:

$$
z=\frac{\bar{Z}}{B} X^{\frac{1}{s}} \Rightarrow \mathrm{d} z=\frac{\bar{Z}}{B s} X^{\frac{1}{s}-1} \mathrm{~d} X
$$

Substitution from Equations (1) and (5) in Equation (2) one gets:

$$
B=\frac{\Gamma(2 / s)}{\Gamma(1 / s)}
$$

where $\Gamma(p)$ is the gamma function.

Substituting from Equations (4), (1) and (5) in Equation (3), we obtain the mean plume velocity:

$$
\bar{U}(z)=U_{r}\left(\frac{\bar{Z}}{Z_{r} B}\right)^{p} \Gamma\left(\frac{p+1}{s}\right) / \Gamma\left(\frac{1}{s}\right)
$$

The mean plume height, $\bar{Z}$, can be calculated according to [9]:

$$
\frac{\mathrm{d} \bar{Z}}{\mathrm{~d} x}=\frac{K(q \bar{Z})}{U(q \bar{Z}) q \bar{Z}}
$$

and

$$
q=\left(s\left(\Gamma\left(\frac{2}{s}\right) / \Gamma\left(\frac{1}{s}\right)\right)^{s}\right)^{1 /(1-s)}
$$

where $K(z)$ is the eddy diffusivity parameterization that is led to the $K$-theory assumption.

According to [10], the form of $K(z)$ in an unstable case is:

$$
\frac{\mathrm{d} \sigma_{y}}{\mathrm{~d} x}=\sigma_{v} /\left(\frac{h^{2} k w_{*} Z_{r}^{p} x}{q^{2}(1-(p / p+1)) U_{r} q^{p}}\right)^{p / p+1} \frac{U_{r}}{\left(Z_{r} B\right)^{p}}\left(\frac{\Gamma\left(\frac{p+1}{s}\right)}{\Gamma\left(\frac{1}{s}\right)}\right)
$$

where

$$
\bar{U}(z)=\left(h^{2} k w_{*} Z_{r}^{p} x / q^{2}\left(1-\frac{p}{p+1}\right) U_{r} q^{p}\right)^{p / p+1} \frac{U_{r}}{\left(Z_{r} B\right)^{p}}\left(\Gamma\left(\frac{p+1}{s}\right) / \Gamma\left(\frac{1}{s}\right)\right)
$$

where $\sigma_{v}$ is the standard deviation of the wind speed in the lateral direction.

By Integrating the Equation (13) with respect to $\mathrm{x}$, we obtain the plume dispersion parameter in the lateral direction $\left(\sigma_{y}\right)$ as follows:

$$
\sigma_{y}(x)=\frac{\sigma_{v} x\left(Z_{r} B\right)^{p}}{\left(h^{2} k w_{*} Z_{r}^{p} x / q^{2}\left(1-\frac{p}{p+1}\right) U_{r} q^{p}\right)^{\frac{p}{p+1}} U_{r}\left(\Gamma\left(p+\frac{1}{s}\right) / \Gamma \frac{1}{s}\right)}
$$

Also estimating the vertical spread $\sigma_{z}$ using hypothesis by [12]:

$$
\frac{\mathrm{d} \sigma_{z}}{\mathrm{~d} x}=\frac{\sigma_{w}}{\left(h^{2} k w_{*} Z_{r}^{p} x / q^{2}\left(1-\frac{p}{p+1}\right) U_{r} q^{p}\right)^{p / p+1}} \frac{U_{r}}{\left(Z_{r} B\right)^{p}\left(\Gamma\left(\frac{p+1}{s}\right) / \Gamma \frac{1}{s}\right)}
$$


where $\sigma_{w}$ is the standard deviation of the wind speed in the vertical direction. Integrating Equation (15) with respect to $\mathrm{x}$, we obtain the plume dispersion parameter in the vertical direction $\left(\sigma_{z}\right)$ as follows:

$$
\sigma_{z}(x)=\frac{\sigma_{w} x\left(Z_{r} B\right)^{p}}{\left(\frac{h^{2} k w_{*} Z_{r}^{p} x}{q^{2}\left(1-\frac{p}{p+1}\right) U_{r} q^{p}}\right)^{\frac{p}{p+1}} U_{r}\left(\frac{\Gamma\left(\frac{p+1}{s}\right)}{\left.\Gamma \frac{1}{s}\right)}\right)}
$$

Then Gaussian expressions for the ground crosswind integrated concentration and the normalized ground level concentration along the plume centerline respectively are given by [4] on the forms:

$$
\begin{gathered}
\frac{C_{y}(x, 0)}{Q}=\sqrt{\frac{2}{\pi}} \frac{1}{U \sigma_{z}} \exp \left(\frac{-h^{2}}{2 \sigma_{z}^{2}}\right) \\
\frac{C_{y}(x, 0,0)}{Q}=\frac{1}{\pi U \sigma_{z} \sigma_{y} \exp \left(-h^{2} / 2 \sigma_{z}^{2}\right)}
\end{gathered}
$$

From the previous works, the plume dispersion parameters in the vertical and lateral directions $\left(\sigma_{z}\right.$ and $\left.\sigma_{y}\right)$ respectly are given by [1] in the form:

$$
\frac{\sigma_{z}^{2}}{z_{i}^{2}}=0.42 \psi^{\frac{2}{3}} x^{2} / 1+\left(2.9 \psi^{\frac{1}{3}} x\right)
$$

and

$$
\frac{\sigma_{y}^{2}}{z_{i}^{2}}=0.55 \psi^{\frac{2}{3}} x^{2} / 1+\left(2.24 \psi^{\frac{1}{3}} x\right)
$$

Also, the plume dispersion parameters in the vertical and lateral directions $\left(\sigma_{z}\right.$ and $\left.\sigma_{y}\right)$ respectively are given by [2] as follows:

$$
\begin{gathered}
\frac{\sigma_{z}^{2}}{z_{i}^{2}}=\left(\frac{0.29}{\pi^{2}}\right) \int_{0}^{\infty} \sin ^{2}\left(0.98 \pi \Psi^{\frac{1}{3}} x n^{\prime}\right) /\left(n^{\prime 2}\left(1+n^{\prime}\right)^{\frac{5}{3}}\right) \mathrm{d} n^{\prime} \\
\frac{\sigma_{y}^{2}}{z_{i}^{2}}=\frac{0.66}{\pi^{2}} \int_{0}^{\infty} \frac{\sin ^{2}\left(0.75 \pi \Psi^{\frac{1}{3}} x n^{\prime}\right)}{n^{\prime 2}\left(1+n^{\prime}\right)^{\frac{5}{3}}} \mathrm{~d} n^{\prime}
\end{gathered}
$$

\section{Results and Discussion}

The used data set was observed from the atmospheric diffusion experiments conducted at the northern part of Copenhagen, Denmark, under unstable conditions [13] and [14]. The tracer sulfur hexafluoride (SF6) was released from a tower at a height of $115 \mathrm{~m}$ without buoyancy. There are two Gaussian models. The First is measured at ground surface and the other at the plume centerline. In this work, there are three predicated normalized concentrations (our model and two previous models) as shown in Tables 1 and 2.

Figures 1 and $\mathbf{2}$ show that the observed and predicated scatter diagram of crosswind integrated concentrations of centerline and ground level respectively using Gaussian model with vertical and lateral dispersion parameters given by (Equations (14) and (16) our model) and (Equations (19) and (20), algebraic formulation), (Equations (21) and (22), integral formulation) respectively. From the two figures one finds that there are some predicated data which are agreement with observed data (one to one) and others lie inside the factor of two.

\section{Statistical Method}

Now, the statistical method is presented and comparison among analytical, statically and observed results will be offered [Hanna 1989, 15]. The following standard statistical performance measures that characterize the agreement between prediction $\left(C_{p}=C_{\text {pred }} / Q\right)$ and observations $\left(C_{o}=C_{o b s} / Q\right)$ :

Normalized mean square error (NMSE): It is an esti-

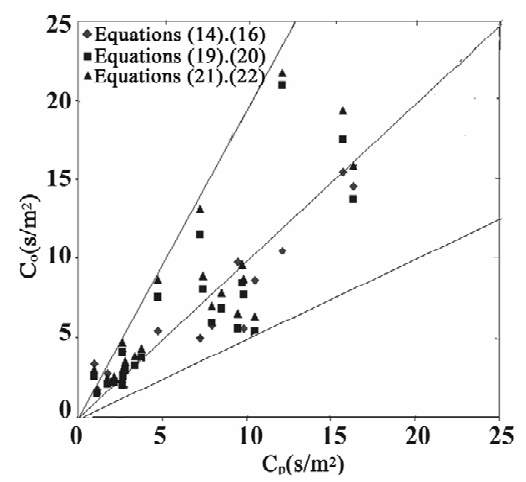

Figure 1. Observed and predicated ground crosswind integrated centerline concentration, normalized with emission $C_{y}(x, 0,0) / Q$ : scatter diagram for the solution of Equation (18) using Equations (14), (16) and (19)-(22).

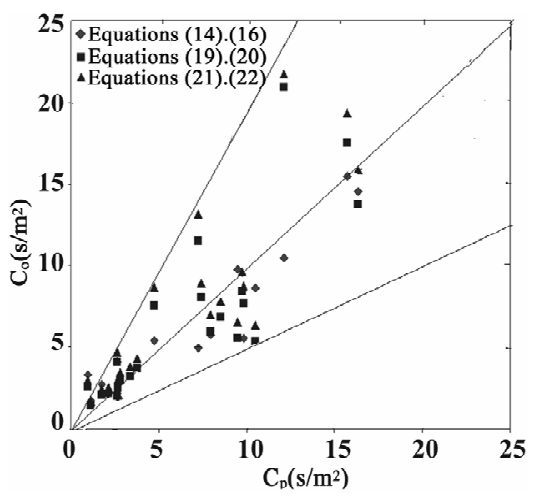

Figure 2. Observed and predicated ground crosswind integrated concentration, normalized with emission $C_{y}(x, 0) / Q$ : scatter diagram for the solution of Equation (17) using Equations (16), (19) and (21). 
Table 1. Observed and model ground-level centerline concentration. $C(x, 0,0) / Q$ at different distances, wind speed and effective height from the source.

\begin{tabular}{|c|c|c|c|c|c|c|c|c|}
\hline \multirow[b]{2}{*}{ Run no. } & \multirow[b]{2}{*}{$\begin{array}{l}\mathrm{h} \\
(\mathrm{m})\end{array}$} & \multirow[b]{2}{*}{ U115 } & \multirow[b]{2}{*}{ distance (x) (m) } & \multirow[b]{2}{*}{$w_{*}$} & \multirow[b]{2}{*}{$\begin{array}{c}C(x, 0,0) / Q\left(\mathrm{~s} / \mathrm{m}^{2}\right) \\
\text { Observed }\end{array}$} & \multicolumn{3}{|c|}{$C(x, 0,0) / Q\left(\mathrm{~s} / \mathrm{m}^{2}\right)$} \\
\hline & & & & & & $\begin{array}{c}\text { Our model } \\
\text { Equations (14), } \\
\text { (16) and (18) }\end{array}$ & $\begin{array}{c}\text { Previous work } \\
\text { Equations (19), } \\
\text { (20) and (18) }\end{array}$ & $\begin{array}{c}\text { Previous work } \\
\text { Equations (21), } \\
\text { (22) and (18) }\end{array}$ \\
\hline 1 & 119 & 3 & 1900 & 1.8 & 10.5 & 8.61 & & 6.37 \\
\hline 1 & 119 & 3 & 3700 & 1.8 & 2.14 & 7.42 & & 2.55 \\
\hline 2 & 117 & 8 & 2100 & 1.8 & 9.85 & 5.55 & 7.67 & 8.71 \\
\hline 2 & 117 & 8 & 4200 & 1.8 & 2.83 & 1.80 & 5.34 & 3.48 \\
\hline 3 & 118 & 4 & 1900 & 1.3 & 16.33 & 14.56 & 2.17 & 15.87 \\
\hline 3 & 118 & 4 & 3700 & 1.3 & 7.95 & 5.77 & 5.95 & 6.98 \\
\hline 3 & 118 & 4 & 5400 & 1.3 & 3.76 & 1.09 & 3.72 & 4.32 \\
\hline 5 & 117 & 5 & 2100 & 0.7 & 15.71 & 15.49 & 17.51 & 19.36 \\
\hline 5 & 117 & 5 & 4200 & 0.7 & 12.11 & 10.49 & 20.94 & 21.73 \\
\hline 5 & 117 & 5 & 6100 & 0.7 & 7.24 & 4.94 & 11.49 & 13.14 \\
\hline 6 & 116 & 11 & 2000 & 2 & 4.75 & 5.43 & 7.52 & 8.69 \\
\hline 6 & 116 & 11 & 4200 & 2 & 7.44 & 2.94 & 8.02 & 8.91 \\
\hline 6 & 116 & 11 & 5900 & 2 & 3.37 & 8.29 & 3.24 & 3.8 \\
\hline 7 & 117 & 7 & 2000 & 2.2 & 1.74 & 2.74 & 2.07 & 2.44 \\
\hline 7 & 117 & 7 & 4100 & 2.2 & 9.48 & 9.78 & 5.55 & 6.54 \\
\hline 7 & 117 & 7 & 5300 & 2.2 & 2.62 & 4.12 & 2.03 & 2.41 \\
\hline 8 & 117 & 7 & 1900 & 2.2 & 1.15 & 1.74 & 1.44 & 1.7 \\
\hline 8 & 117 & 7 & 3600 & 2.2 & 9.76 & 3.22 & 8.43 & 9.62 \\
\hline 8 & 117 & 7 & 5300 & 2.2 & 2.64 & 1.96 & 4.06 & 4.69 \\
\hline 9 & 116 & 8 & 2100 & 1.9 & 0.98 & 3.34 & 2.59 & 2.96 \\
\hline 9 & 116 & 8 & 4200 & 1.9 & 8.52 & 1.52 & 6.86 & 7.85 \\
\hline 9 & 116 & 8 & 6000 & 1.9 & 2.66 & 6.75 & 2.55 & 3.04 \\
\hline
\end{tabular}

Table 2. Observed and model ground-level concentration $C_{y}(x, 0) / Q$ at different distances, wind speed and effective height from the source.

\begin{tabular}{|c|c|c|c|c|c|c|c|c|}
\hline \multirow[b]{2}{*}{ Run no. } & \multirow[b]{2}{*}{$\begin{array}{l}\mathrm{h} \\
(\mathrm{m})\end{array}$} & \multirow[b]{2}{*}{ U115 } & \multirow[b]{2}{*}{ distance (x) (m) } & \multirow[b]{2}{*}{$w *$} & \multirow{2}{*}{$\begin{array}{c}C(x, 0) / Q \\
\left(\mathrm{~s} / \mathrm{m}^{2}\right) \\
\text { Observed }\end{array}$} & \multicolumn{3}{|c|}{$C(x, 0) / Q\left(\mathrm{~s} / \mathrm{m}^{2}\right)$} \\
\hline & & & & & & $\begin{array}{c}\text { Our model } \\
\text { Equations (16) and (17) }\end{array}$ & $\begin{array}{c}\text { Previous work } \\
\text { Equations (17) and (19) }\end{array}$ & $\begin{array}{c}\text { Previous work } \\
\text { Equations (17) and (21) }\end{array}$ \\
\hline 1 & 119 & 3 & 1900 & 1.8 & 6.48 & 3.72 & 6.06 & 6.58 \\
\hline 1 & 119 & 3 & 3700 & 1.8 & 2.31 & 4.61 & 3.96 & 4.28 \\
\hline 2 & 117 & 8 & 2100 & 1.8 & 5.38 & 4.66 & 3.64 & 3.79 \\
\hline 2 & 117 & 8 & 4200 & 1.8 & 2.95 & 2.46 & 2.48 & 2.68 \\
\hline 3 & 118 & 4 & 1900 & 1.3 & 8.2 & 7.92 & 7.35 & 7.72 \\
\hline 3 & 118 & 4 & 3700 & 1.3 & 6.22 & 1.23 & 5.22 & 5.6 \\
\hline 3 & 118 & 4 & 5400 & 1.3 & 4.3 & 2.21 & 4.22 & 4.52 \\
\hline 5 & 117 & 5 & 2100 & 0.7 & 6.72 & 8.24 & 8.54 & 8.77 \\
\hline 5 & 117 & 5 & 4200 & 0.7 & 5.84 & 2.63 & 6.04 & 5.71 \\
\hline 5 & 117 & 5 & 6100 & 0.7 & 4.97 & 4.65 & 5.73 & 5.96 \\
\hline 6 & 116 & 11 & 2000 & 2 & 3.96 & 3.30 & 4.9 & 5.19 \\
\hline 6 & 116 & 11 & 4200 & 2 & 2.22 & 4.41 & 3.14 & 3.18 \\
\hline 6 & 116 & 11 & 5900 & 2 & 1.83 & 1.06 & 2.31 & 2.47 \\
\hline 7 & 117 & 7 & 2000 & 2.2 & 6.7 & 4.63 & 1.9 & 2.04 \\
\hline 7 & 117 & 7 & 4100 & 2.2 & 3.25 & 1.09 & 3.69 & 4.25 \\
\hline 7 & 117 & 7 & 5300 & 2.2 & 2.23 & 1.48 & 2.14 & 2.73 \\
\hline 8 & 117 & 7 & 1900 & 2.2 & 4.16 & 5.16 & 4.12 & 2.31 \\
\hline 8 & 117 & 7 & 3600 & 2.2 & 2.02 & 2.91 & 3.12 & 4.28 \\
\hline 8 & 117 & 7 & 5300 & 2.2 & 1.52 & 2.50 & 2.56 & 3.31 \\
\hline 9 & 116 & 8 & 2100 & 1.9 & 4.58 & 3.04 & 3.53 & 2.71 \\
\hline 9 & 116 & 8 & 4200 & 1.9 & 3.11 & 2.19 & 2.34 & 3.7 \\
\hline 9 & 116 & 8 & 6000 & 1.9 & 2.59 & 4.04 & 1.85 & 2.54 \\
\hline
\end{tabular}


mator of the overall deviations between predicted and observed concentrations. Smaller values of NMSE indicate a better model performance. It is defined as:

$$
N M S E=\frac{\overline{\left(C_{o}-C_{p}\right)^{2}}}{\bar{C}_{o} \bar{C}_{p}}
$$

Fractional bias (FB): It provides information on the tendency of the model to overestimate or underestimate the observed concentrations. The values of FB lie between -2 and +2 and it has a value of zero for an ideal model. It is expressed as:

$$
F B=\frac{\left(\bar{C}_{o}-\bar{C}_{p}\right)}{0.5\left(\bar{C}_{o}+\bar{C}_{p}\right)}
$$

Correlation coefficient (R): It describes the degree of association between predicted and observed concentrations and is given by:

$$
R=\frac{\overline{\left(C_{o}-\bar{C}_{o}\right)\left(C_{p}-\bar{C}_{p}\right)}}{\sigma_{o} \sigma_{p}}
$$

Fraction within a factor of two (FAC2) is defined as: $\mathrm{FAC} 2=$ fraction of the data for which

$$
0.5 \leq\left(C_{p} / C_{o}\right) \leq 2
$$

where $\sigma_{p}$ and $\sigma_{o}$ are the standard deviations of $C_{p}$ and $C_{o}$ respectively. Here the over bars indicate the average over all measurements $(\mathrm{Nm})$. A perfect model would have the following idealized performance: $\mathrm{NMSE}=\mathrm{FB}=0$ and $\mathrm{COR}=\mathrm{FAC} 2=1.0$ of the entire journals, and not as an independent document. Please do not revise any of the current designations.

From the statistical method of Table 3, we find that the predicted concentrations for all models lie inside factor of 2 with observed data. Regarding to NMSE, we find that two previous works are better than our model. Regarding to FB and correlation coefficient of all models are agreement with observed data.

Table 4 shows that the predicted concentrations for all models lay inside factor of 2 with observed data. Regarding to NMSE, all the predicted concentrations are better to the observed data. Regarding to FB and correlation coefficient of all methods are agreement with observed data.

\section{Conclusions}

New schemes of dispersion parameters in the lateral direction $\left(\sigma_{y}\right)$ and the vertical direction $\left(\sigma_{z}\right)$ are estimated in unstable stability by using power law wind speed and calculating Gaussian plume model at ground and at plume centerline.

One used observed data of the tracer sulfur hexafluo-
Table 3. Comparison between different models groundlevel centerline concentration $C_{y}(x, 0,0) / Q$ and observed concentrations.

\begin{tabular}{ccccc}
\hline Predicted models $C_{y}(x, 0,0) / Q$ & NMSE & FB & COR & FAC2 \\
\hline $\begin{array}{c}\text { Our model Equations (14), } \\
\text { (16) and (18) }\end{array}$ & 0.28 & 0.12 & 0.72 & 1.22 \\
$\begin{array}{c}\text { Previous work Equations } \\
\quad(19),(18) \text { and (20) }\end{array}$ & 0.18 & -0.02 & 0.83 & 1.12 \\
$\begin{array}{c}\text { Previous work Equations } \\
(18),(21) \text { and (22) }\end{array}$ & 0.18 & -0.14 & 0.86 & 1.28 \\
\hline
\end{tabular}

Table 4. Comparison between different models groundlevel centerline concentration $C_{y}(x, 0) / Q$ and observed concentrations.

\begin{tabular}{ccccc}
\hline Predicted models $C_{y}(x, 0) / Q$ & $\mathrm{NMSE}$ & $\mathrm{FB}$ & $\mathrm{COR}$ & $\mathrm{FAC} 2$ \\
\hline $\begin{array}{c}\text { Our model Equations (16) } \\
\text { and (17) }\end{array}$ & 0.13 & 0.07 & 0.90 & 1.09 \\
$\begin{array}{c}\text { Previous work Equations } \\
\text { (17) and (19) }\end{array}$ & 0.11 & 0.03 & 0.72 & 1.05 \\
$\begin{array}{c}\text { Previous work Equations } \\
(17) \text { and (21) }\end{array}$ & 0.14 & -0.03 & 0.64 & 1.15 \\
\hline
\end{tabular}

ride (SF6) which was released from a tower at a height of $115 \mathrm{~m}$ without buoyancy at the northern part of Copenhagen, Denmark, under unstable conditions $[13,14]$. There are two Gaussian models; The First is measured at ground surface and the other at the plume centerline. In this work, there are three predicated normalized concentrations (our model and two previous models).

From the (Figures 1 and 2), one finds that there are some predicated data which are agreement with observed data (one to one) and others lie inside the factor of two

From the statistical method, we find that the predicted concentrations for all models lie inside factor of 2 with observed data. Regarding to NMSE, all the predicted concentrations are agreement with the observed data. Regarding to FB and correlation coefficient of all methods agree to observed data.

\section{REFERENCES}

[1] L. Buligon, G. A. Degrazia, C. R. P. Szinvelski and A. G. Goulart, "Algebraic Formulation for the Dispersion Parameters in an Unstable Planetary Boundary Layer: Application in the Air Pollution Gaussian Model," The Open Atmospheric Science, Vol. 2, No. 1, 2008, pp. 153-159.

[2] F. Pasquill and F. B. Smith, "Atmospheric Diffusion," Ellis Howood Ltd., Chichester, 1983.

[3] J. F. C. Meyer and G. L. Diniz, "Pollutant Dispersion in Wetland Systems: Mathematical Modeling and Numerical Simulation," Ecological Modelling, Vol. 200, No. 3-4, 2007, pp. 360-370. doi:10.1016/i.ecolmodel.2006.08.005 
[4] S. E. Arya, "Air Pollution Meteozrology and Dispersion," Oxford University Press, New York, 1999.

[5] S. A. Abdual-Wahab, "The Hole of Meteorology on Predicting $\mathrm{SO}_{2}$ Concentrations around a Refinery: A Case Study from Oman," Ecological Modelling, Vol. 197, No. $1-2,2006$, pp. $13-20$. doi:10.1016/j.ecolmodel.2006.02.021

[6] A. Venkatram, "The Role of Meteorological Inputs in Estimating Dispersion from Surface Releases," Atmospheric Environment, Vol. 38, No. 16, 2004, pp. 2439-2446. doi:10.1016/j.atmosenv.2004.02.005

[7] S.-E. Gryning, P. Van Ulden and E. R. Larsen, "Dispersion from a Continuous Ground-Level Source Investigated by a K Model," Quarterly Journal of the Royal Meteorological Society, Vol. 109, No. 460, 1983, pp. 355364.

[8] J. S. Irwin, "A Theoretical Variation of the Wind Profile Power Law Exponent as a Function of Surface Roughness and Stability," Atmospheric Environment, Vol. 13, No. 1, 1979, pp. 191-194. doi:10.1016/0004-6981(79)90260-9

[9] A. P. Van Ulden, "Simple Estimates for Vertical Dispersion from Sources near the Ground," Atmospheric Environment, Vol. 12, No. 11, 1978, pp. 2125-2129. doi:10.1016/000,4-6981(78)90167-1

[10] J. E. Pleim, "A Nonlocal Closure Mode for Vertical Mixing in the Mixing in the Convective Boundary Layer,"
Atmospheric Environment. Part A. General Topics, Vol. 26, No. 6, 1992, 965-981. doi:10.1016/0960-1686(92)90028-J

[11] G. A. Briggs, "Plume Rise," U.S. \& Atomic Commission, Division of Technical Information, 1969.

[12] R. M. Eckman, "Re-Examination of Empirically Derived Formulas for Horizontal Diffusion from Surface Sources," Atmospheric Environment, Vol. 28, No. 2, 1994. pp. 265-272. doi:10.1016/1352-2310(94)90101-5

[13] S. E. Gryning and E. Lyck, "Atmospheric Dispersion from Elevated Sources in an Urban Area: Comparison between Tracer Experiments and Model Calculations," Journal of Climate and Applied Meteorology, Vol. 23, No. 4, 1984, pp. 651-660. doi:10.1175/1520-0450(1984)023<0651:ADFESI $>2.0$.C $\mathrm{O} ; 2$

[14] S. E. Gryning, A. A. M. Holtslag, J. S. Irwin and B. Sivertsen, "Applied Dispersion Modeling Based on Meteorological Scaling Parameters," Atmospheric Environment, Vol. 21, No. 1, 1987, pp. 79-89. doi:10.1016/0004-6981(87)90273-3

[15] S. R. Hanna, "Confidence Limit for Air Quality Models as Estimated by Bootstrap and Jackknife Resembling Methods," Atmospheric Environment, Vol. 23, No. 6, 1989, pp. 1385-1395. doi:10.1016/0004-6981(89)90161-3 